choses qui concerne son art c'est en celle où il s'agit de juger si l'enfant qui est dans la matrice est vivant où bien s'il est mort." Here, certainly, were many of the symptoms of a devitalised pregnancy; as cessation of the child's movements; sensation of coldness, and weight in the abdomen; fetid slimy discharge per vaginam; and what Dr. Rigby thinks the most trustworthy, the sensation of a heavy weight rolling about the abdomen; for a woman who is pregnant with a living child feels nothing of the sort; she may even dance or jump, and yet she feels no more of a living fotus than she does of her own liver or spleen. The living fœtus obeys the laws of organic life; the dead, those of gravity. From these symptoms, then, we cannot wonder at the medical men pronouncing that the fotus must be dead; but what a different opinion would they have formed, had they only made a careful examination with the stethoscope; for the sound of the fotal heart must be regarded as a sign of the highest value; since, however complicated and obscure the other symptoms may be, whether from co-existing disease or wilful deception, if this sound be once heard unequivocally, the real nature of the case is satisfactorily established beyond the possibility of donbt.

The uterine souffle is the first sound which auscultation detects, and may be heard as early as the fifteenth or sixteenth week, extending over the whole uterus; from the diminutive size of which, it can be heard most readily immediately above the symphysis pubis.

The beat of the fœtal heart, indeed, is attended with such a peculiar sharp and rapid tick, that it can scarcely be mistaken, and is usually heard at about the middle point, between the scrobiculus cordis and symphysis pubis, usually to one side, and that generally speaking, the left. With regard to the fotal pulsations, we find them generally beating at the rate of 130 to 150 double strokes in a minute; and the age of the fotus appears to have no effect upon the rapidity, for even at the earliest periods at which we can detect these sounds, the rate of the pulsation is the same as at the full term of pregnancy. In conclusion, then, Gentlemen (for I had no intention of trespassing so long upon your valuable columns), I do boldly contend that, if by the simple application of the stethoscope to the abdomen of the parturient woman, we can decide in a doubtful case on the present state of fœtal vitality, we are gaining the greatest possible advantage, without subjecting the patient to the least pain, danger, or inconvenience, and even without shocking, in the slightest degree, the most delicate or sensitive mind, since it is not required that the whole of the dress should be removed.

\section{CASE OF RARE MALFORMATION.}

TO THE EDITORS OF THE PROVINCIAL MEDICAL AND SURGICAL JOURNAL.

Gentlemen,- - Should you consider the following account of a malformation to be of sufficient interest, I shall feel obliged by your giving it an early insertion in your pages.

\section{I am, Gentlemen,}

\section{Your obedient servant} James Orwin,

Surgeon to the Worcester Ophthalmic Institution. Worcester, Feb. 24, 1842 .
Mrs. J - was delivered of a daughter on the 15 th of August, 1841. The labour was perfectly natural. On examining the infant, I discovered a fissure in the integuments over the lower portion of the spinal column, and on separating it a thin, semitransparent cuticle, similar to that raised by a blister, could be seen. At my next visit, on the following day, this thin cuticle had burst in one part, and I, therefore, dissected it away, to ascertain the state of the parts underncath. On passing the end of one finger into the fissure, I found I could move it under the integnments, as there was a sort of pouch in this situation. When pressure was made towards the pelvis, no bony resistance could be felt; and on carrying the fingers of the other hand along the spinal column, I discovered that it terminated at the upper part of the fissure, and at a point which corresponded to the middle of the sacrum, so that the lower part of that bone, and the whole of the coccyx, were entirely wanting. Dividing the pouch from the cavity of the pelvis, and occupying the place of the absent coccyx and lower part of the sacrum, was a rather firm membrane of a bluish tinge, which, when pressure was made upon it, gave the sensation of there being semifluid matter under it, such as the usual contents of the rectum. When the child cried, this membrane was distended. In order to ascertain its connection with the rectum, I passed a female catheter through the anus, and, as feculent matter escaped, the membrane became less distended. I then turned the end of the catheter towards the membrane, when I could easily feel it through this structure, and through the coats of the bowel, by the end of my finger, when placed in the fissure. This membrane was, in fact, the only protection which the rectum had from anything passed through the fissure in the integuments. The child was well formed in other respects, and there was no paralysis of the lower extremities to lead to the supposition of the malformation having any connection with the spinal nerves. The bowels and bladder evacuated their contents in a perfectly natural manner.

The case was seen by several of the medical gentlemen of this city, none of whom had witnessed a similar one; nor can I find such an one described in any work I have consulted. It cannot be regarded simply as a case of spina bifida, for that term is usually applied to a deficiency of the posterior part of the rings of the vertebræ; whereas, in the case under consideration, the lower portion of the spinal column was entirely absent.

The defect was fortunately below that portion of the sacrum which is connected with the ossa innominata, so that the spinal column was properly supported by the lower extremities. I know of no explanation which can be given of this case, except that it is to be considered as an illustration of what is termed "arrest of development;" but why Nature should leave her work incomplete in this situation, I must leave to more profound embryologists than myself to determine.

As it did not appear prudent to attempt any operation on a newly-born infant, the case was left to nature. I was rather apprehensive that the membrane covering the rectum would slough, so as to expose that gut, and perhaps lead to an artificial anus ; but this disaster has not occurred : the membrane has become converted into a sort of internal integument, which has partly united to the surrounding structures, and when pressure is made towards the pelvis, a tolerable degree of resistance is experienced. The external fissure, however, still remains; and the natural integument not having become completely adherent to the internal one, formed from the original membrane, the pouch or bag is not obliterated. The child is now about six months old, and appears strong and healthy. As there does not seem any probability of the external fissure closing, or of the integuments becoming adherent to that beneath it, I feel anxious 
to effect a consolidation between the two skins by the use of potassa fusa, and then to pare the edges of the fissure, and unite them by sutures. Such an operation would, I think, assist Nature in her endeavours to make up for the absence of the proper bony support at the posterior and inferior portion of the pelvis. The parents, however, object at present to have anything attempted. Should they consent, I shall be happy to communicate the result of the operation.

\section{PROVINCIAL}

\section{MEDICAL \& SURGICAL JOURNAL}

\section{SATURDAY, MARCH 5, 1842.}

The earlier phrenologists, following the ideas of Dr. Spurzheim, had pointed out an unappropriated space in their craniological maps, situated immediately above that allotted to Ideality, as the local habitation of a faculty, to which Dr. Spurzheim gave the name of surnaturalité, but which, extended somewhat in its signification, was, by Mr. George Combe, more appropriately designated Wonder. The limits of this terra incognita were circumscribed by the organs Hope, Wit, Imitation, and the aforesaid organ, Ideality. It is stated by Dr. Spurzheim that the faculty connected with this organ, surnaturalité, produces, as its name indicates, the tendency to believe in inspirations, presentiments, phantoms, \&c.; and Mr. Combe, in commenting upon these views of his great leader, says, "I have met with persons excessively fond of news, which, if extravagant, were the more acceptable; prone to the expression of surprise and astonishment in ordinary discourse; deeply affected by tales of wonder; delighting in the Arabian Nights' Entertainments, and the mysterious incidents abounding in the Waverley Novels; and in them I have uniformly found the part of the brain in question largely developed."

Whatever we may be disposed to think of the investing of that portion of the cerebral ganglia which lies immediately beneath this peculiar spot of the cranium, with the faculty in question, we can neither doubt of the existence of the sentiment, nor fail to admire the tact with which phrenologists have located it. It may, however, admit of question, assuming the principles of Dr. Spurzheim and Mr. Combe to be correct, that the chief end of the faculty or sentiment has been yet clearly made out, and that the designation of the organ, through which it is presumed to be manifested, is as expressive as it might have been. Following Mr. Combe, we can by no means admit that the faculty, with the limitation implied under the term surnaturalité, is correctly characterised and named; but, on the other hand, neither do we altogether subscribe to the opinion that every feeling of surprise, and the mixed emotions of admiration or terror often consequent thereupon, or rather interwoven therewith, however they may be classed under the general term Wonder, should be ascribed to the unassisted activity of this organ. Circumscribed as is this spot, and as it were blended in indissoluble connection with the neighbouring organs, Wit, Ideality, Imitation, and Hope, and especially the three last, we cannot but look upon it as intended for the conjoint manifestation of the assemblage of faculties here brought together, and thus forming a compound organ, admirably adapted to express the sentiment, and give effect to the principle, the leading manifestations of which are so extensively exhibited throughout all classes of society, in a country not unaptly termed the paradise of empirics.

If we look to those peculiar mental qualities, the ill-regulated operation of which tends to unfounded credulity, we shall see that Ideality, Wonder, Hope, and Imitation, are greatly concerned in the production of the sentiment. Empirical pretensions, while they require, to invest them with interest, some dash of that faculty by which incongruous relations are perceived, are mainly indebted for their reception by the human mind to the imaginative powers of the recipient, the surprise by which they disarm his judgment, and the expectations of personal advantage to which they give rise. "Afferim !"-wonderful!-is the exclamation of the Turk, as he swallows, with the extreme of hope and credulity, the nostrums of the Jew resident, or the James's powder of the Christian traveller, both of them, perhaps, guiltless of medical knowledge. "Wa! wa!" cries the Hindoo, at every display of skill or jugglery, as the case may be, with which a white man may condescend to play upon or attempt to enlighten his understanding. The truth is, the appetite for the marvellous is insatiable. It is a principle in human nature, and the highly cultivated man of civilised life is equally subject with the untutored savage to its dominant influence. 'The only difference is, that the former, through his education and the general cultivation of his mind, is kept from manifesting it so generally as the latter. The one and the other show it more or less whenever they are in ignorance; the educated man, therefore, in much that passes before him; the illiterate child of nature in everything.

Upon these principles, profoundly ignorant as mankind in general are of the structure and functions of their own frame, and of all that relates to it, whether in health or disease, it is to be expected that empiricism will be encouraged, and that quacks will abound. It might have been supposed, perhaps, that by the highly seasoned pabulum with which the taste for empirical wonders has lately been gratified, the appetite would have been somewhat palled; but, after indulgence in the debauch of one day, there is little disposition for a simple and wholesome nutriment on the following. As the old delusions lose somewhat of their novelty, and having lasted their day, are no longer capable of satisfying the demands of a craving gullibility, new ones arise to take their place. St. John Long, with his metallic distillation from the backs of his patients, as witnessed by a noble officer in her Majesty's naval service, and other distinguished personages, rests in the tomb of the Capulets. The 